\title{
Spoken Language Features Used by Teachers in the Early Bilingual Classroom
}

\author{
Citra Putri Utami, Junnilalita Aisya Virgin \\ Semarang State University, Semarang, Indonesia \\ Citrautami2110@gmail.com
}

\begin{abstract}
English teacher at schools must be seen as a person who can speak English well. The students believe that they are the source of the target language. Thus, it is quite interesting to investigate the language used by teachers in the immersion school to interact with the students in the classroom. This case study was conducted at Mondial Primary School involving two teachers of grade 3.The result shows that the teachers have already used various language features in their talk to early bilingual students in the classroom. They are: idiomatic units such as sit down, blown up, listen up, write down, turn over; collocations such as listen that co-occurs with to, deals-occurs with with, take cooccurs with a look; binomial expressions which are connecting verbs with "and" such as shivering and freezing, listen and watch; the minor clauses (inserts) such as the discourse marker like alright, okay, well, now, please, by the way, what is it, I mean, excuse me; and the lexical bundles such as I'dliketotel you that, I will show you how, can you please, what do you know about, what will happen if.
\end{abstract}

Keywords: early bilingualism, teacher talk, spoken language features

\section{INTRODUCTION}

The study investigates spoken language features (SLFs) used by teachers in the early bilingual classroom. This study is motivated by the fact that according to Vygotsky in Smidt (2009), every function in the child's cultural development appears twice: first, on the social level, and later on the individual level; first, between people (inter-psychological) and then inside the child (intra-psychological). Mediation is the central of Vygotsky's theory that the concepts show how the child is moved from social level to individual level of learning. The concepts are internalization, participation, and memory (Smidt, 2009). Internalization is where the children become the part of a community and share with the adults. Participation is where the children have a kind of stimulus given by the adults to communicate such as to share their ideas and express their feeling. Memory is where the input the children get from the environment including the language used by the adults absorbed. Thus, the presence of teachers should not only give the materials and introduce them the theories but also involve them in real conversation through teachers' scaffolding talk. Scaffolding is a kind of strategy that can be used to provide assistance through classroom interaction so that learners can accomplish the tasks with assistance and pass through their zone of proximal development or ZPD. Therefore, the guidance, support, and aid from teachers are very useful to achieve the desired expression emerged in the interaction that will become the language input for students.
Another fact is that the primary goal of teaching and learning English is Communicative Competence (CC) which is aimed to enable the students to be fluent and accurate to create texts based on the context. Communicative competence represents discourse competence. Discourse competence is formed by many components also such as socio- cultural, actional, linguistic, and strategic competence (Celce- Murcia, 2007). Those components are interacting with each other to form discourse competence. It means that discourse competence can be achieved when the language learners master the supporting competence such as linguistic competence, actional competence, socio-cultural competence and strategic competence. Furthermore, teachers should consider those aspects in applying the teaching method and selecting the lesson materials. Then, there is rethinking of the role of communication competence that includes a new competence which is the counterbalance of linguistic competence, that is, formulaic competence (Celce- Murcia, 2007).

Formulaic competence refers to those fixed and prefabricated chunks of language that the native speakers use in everyday interactions such as collocations, idioms, lexical frames and routines. In creating a spoken text in communication, chunks have a great deal to help the students to use language appropriately since it is grammatical and have suitable words to use also. As it is stated by Widdowson (1989:135) that "communicative competence is not a matter of knowing rules for the composition of sentences and being able to employ such rules to assemble expressions from scratch as and when occasion requires. It is much more a matter of knowing a stock of partially pre-assembled patterns, formulaic frameworks, and a kit of rules, so to speak, and being able to apply the rules to make whatever adjustments are necessary according to contextual standards."

Since Celce-Murcia only mention the general attentions generated by the seminal work of Nattinger and DeCarrico (1992), the corpus linguistic of Lexical Bundles from Biber et al. will add the specification of types of SLFs used by teachers include collocations, idiomatic phrases, binomial expressions, inserts (minor clauses), and lexical bundles.

(1) Collocations consist of independent words that tend to co-occur (Biber et al., 1999:59). For example, the adjectives broad and wide are found in different collocations even they have the same meaning. We cannot say broad area or broad selection but the word 'wide' is the correct word to combine with collocates 'area' and 'selection'. 
(2) Idiomatic Phrases are 'the expressions with a meaning not entirely derivable from the meaning of their parts and can represent many different kinds of structural units' (Biber et al., 1999). There are two categories of idiomatic phrases according to Biber et al. (1999:1025): verb + prepositional phrase idioms such as fall in love, and verb + noun phrase idioms such as kick the bucket.

(3) According to Biber et al. (1999:1030), binomial phrases consist of two words from the same grammatical category, coordinated by 'and' or 'or' such as fish and chips, mum and dad, go and get, etc.

(4) Inserts can be categorized as formulaic expressions since it has implicit meaning either it is a word (single morpheme) like yes, no, please, okay, etc. or word string (invariable lexicalized sequence) like you know, I mean, thank you, etc.

(5) Biber et al. (1999) classified the structural characteristics of bundles into three types: lexical bundles that incorporate verb phrase fragments (e.g. you don't have to, it's going to be, I mean you know, are you going to, what do you think), lexical bundles that incorporate dependent clause fragments (e.g. I don't want you to, what I want to, if you want to, to be able to, that there is a) and lexical bundles that incorporate noun phrase and prepositional phrase fragments (e.g. one of the things, a little bit about, at the end of, as far as)

Thus, some major categories of lexical bundles in conversation can be probably found in the expressions used in the interaction between teacher and students in the classroom. Those all the categories of formulaic expressions will indicate the spoken language features used to communicate. According to that, the SLFs that are investigated in this study identified from the fixed and prefabricated chunks found in the teachers' talk.

In Indonesia, nowadays there are some schools adopt immersion programs. In Semarang, Mondial Education adopts an early immersion program within pre-school years until primary school years where both teachers and students are demanded to use English actively in any situation when they are at school aiming at forming English as a habit. Immersion program as a method of foreign language instruction in which the regular school curriculum is taught through the medium of the language. In this program nearly all instruction is in English, and there is little or no use of other languages. According to that, the teachers who are non- native speakers of English strive to improve students' spoken language to communicate by engaging the students in the interaction in order to stimulate the receptivity and the willingness of the students to encounter the language in a daily communication.

Therefore, this study is conducted to provide the information about the spoken language features used by teachers in the classroom to a betterment of teacher performance and students' quality in early childhood education.

\section{METHODS}

\subsection{RESEARCH APPROACH}

In conducting the study, I used qualitative research since the focus of doing this research is to observe the participants' behavior during their engagement in activities to know the spoken language features emerged in the teachers' talk.

\subsection{DATA COLLECTION}

The data were taken in the form of videotapes consisting conversation's transcript between the teachers and the students in the classroom of grade 3 of Mondial Schools in Semarang. The quantitative data is only about the frequency of occurrence of each type of spoken language features in teachers' talk. The data collection in this study involves four stages as suggested by Creswell (2014:190). First, I identified the purposefully selected sites or individuals to be the objects of study. The next step was deciding the number of participants. I took two teachers as the sources of my data. Then, I collected the qualitative data that consist of qualitative audio and visual materials. All the data obtained from those steps were transcribed.

\subsection{DATA ANALYSIS AND INTERPRETATION}

The data were analyzed after getting the audio and video recordings. The first step was preparing the transcript which was presented in a form of a table. The next step was reading or looking at the data and trying to make the general thoughts about the data collected. After that, I started coding the data. In case of the present study, I classified the teachers' talk into the language functions based on Hughes (1981:9) and then into the types of spoken language features based on Biber et al. (1999). As this study focused on the teachers' talk, the students' speech production were not analyzed. The next step is calculating the frequency of occurrence of each types and then the result was displayed into a table of occurrence.

The data interpretation was conducted through several stages. The first step of interpreting the data is telling the frequency of the types of spoken language features produced by the teachers. After that, the data were then interpreted based on the references. The classroom context concerning the topic of the lesson and the activities provided by the teachers was described clearly to accompany the excerpts of the spoken language features found.

\section{DISCUSSION}

Table 1. The table shows the type of SLFs emerged in teachers' talk as well as their frequency of occurrence.

\begin{tabular}{lc}
\multicolumn{1}{c}{ Types of SLFs } & $\begin{array}{c}\text { Occurrence of Teachers' } \\
\text { production }\end{array}$ \\
\hline Collocations & $\mathbf{1 6 6}$ \\
Adjectives - Nouns & 41 \\
Nouns - Verbs & 27 \\
Noun - Noun & 36 \\
Verbs - Preposition & 15 \\
Verbs - Adverbs & 4 \\
Verbs - Adjectives & 6 \\
Adverbs - Adjectives & 12 \\
Adverbs - Adverbs & 2 \\
Collocations in & prepositional \\
phrases & 25 \\
\hline Idiomatic phrases & $\mathbf{2}$ \\
\hline
\end{tabular}


Table 1, Cont.

\begin{tabular}{lc} 
Binomial expressions & $\mathbf{1 4}$ \\
Noun and/or noun & 7 \\
Adjective and/or adjective & 5 \\
Verb and/or verb & 2 \\
Inserts & $\mathbf{1 9 6}$ \\
Greetings and farewell & 2 \\
Discourse marker & 85 \\
Response elicitors & 3 \\
Response form & 64 \\
Polite formulae & 37 \\
Vocatives & 5 \\
\hline Lexical Bundles (LB) & $\mathbf{2 0 5}$ \\
Lexical bundles that incorporate verb phrase fragments & 146 \\
Lexical bundles that incorporate dependent clause fragments Lexical & 52 \\
bundles that incorporate noun phrase and prepositional phrase & 7 \\
fragments & \\
\hline
\end{tabular}

It can be seen from the table that the teachers used various types of SLFs. Those SLFs were almost used by teachers in every utterance to interact with the students. The most frequent SLFs used were lexical bundles, inserts, and collocations because they were used more than 150 times compare to other types, for instance idiomatic phrases (7 times) and binomial expressions (14 times). In the classroom situation, the teachers tried to encourage students' participation by giving questions so there would be lexical bundles in the form of wh-question fragment and yes-no question fragment such as "what do you know about", "what is the", "anyone knows?", "any questions?".

By giving those questions, automatically the teachers also gave the feedback towards students' answers as well as gave the appreciation such as by saying 'that's a good idea'. More, the teacher often added the explanation about some factual information. Inside the explanation, there were some bundles, such as "we can be easily sick if" to express cause and effect; "there is a" to mention an object; "when it is going to" which is a bundle as dependent clause and "many kinds of" that refers to a bundle incorporate with noun phrase.

Besides that, the SFL also often exists with functional grammar as directive or imperative meaning/giving order because the teacher implemented various content of learning that involved students' participation so the teachers actively gave instructions as guidance. There are several examples in this case. The teachers used idiomatic phrase and collocation "let's read first.", "take a look at" to direct pupil's attention to the whiteboard or the textbook. "I want you to" and "You don't need to" are commands in the form of declarative clause. "Can you please repeat" has insert "please" which is to assist imperative clause as polite formulae or discourse marker, or in six-word bundle "what you have to do is". Another example is the imperative clauses in multi-words units such as "come on" that was said by teacher to encourage students to speak and "listen up" is to warn the students who were not serious in following the lesson.

Idiomatic phrases were used to give command, such as 'line up, 'tidy up' and 'one by one, please'. Binomial expression such as 'listen and watch them!' was also used to give command. In as much as the teacher encourage student to be active, teacher implemented play-based learning so they used some utterances to sign a transition for a new topic or activity, such as "okay", "now”, “so", "well”. Those utterances made teacher's talk to be more interactive. Besides, a bundle "we are going to" was also used by teachers.

The using of SFL which are identified by the fixed and prefabricated chunks in the teachers' talk can give positive impact towards students' language development. The teachers indirectly gave model to the students in using the utterances. For example, when the teacher tried to connect weather, topic at that time, with windmill for pilot in the airport, the teacher explained and used illustration made in whiteboard. In verbal commentary that accompanying the picture, the teacher said "take off" and "turn over". A lot of students did not know what the meaning of those words. Therefore, the teacher gave verbal commentary and linked the material to illustration in daily life. During the commentary, it is often that there are some words have not been understood by students so it is a good input for students for their future language development.

It is also found that the teacher used collocations, and then the pattern was followed by the students. For instance, when the teacher used "sunny day" and "drizzle day" then the students imitated that utterance. Other finding is that the students tend to be more active to ask question if they found some words they did not understand yet. For example, when the student asked about the meaning of "overcast", then the teacher tried to give clue by saying "overcast sky". Other student could guess the meaning of "overcast" because it is about sky. Furthermore, the teacher also used collocation to mention place information, such as "in the sky", "in the dessert", etc. Those kind of input are beneficial to students.

\section{CONCLUSION}

There are some important points or findings based on the data analysis and the conclusions can be drawn as follows.

First, the two teachers used various spoken language features in the interaction with students. They are idiomatic phrases, collocations, binomial expressions, inserts, and lexical bundles. Idiomatic phrases were mostly used as imperative clauses such as "take a look", "line up", and "tidy up". Collocations mostly occurred in the form of adjectives and nouns collocations such as "good idea" and "enough sunlight". The teachers used many kinds of inserts such as "Good morning" for greeting; "okay" as discourse marker; "right" as a question tag; "please" as the polite formulae; and "guys" to single out the addressee of a message in a question or statement. Binomial expression such as 'listen and watch them!' was also used to give command. Lexical bundles were mostly used in the form of wh-question fragments which mostly began with "what' such as "what do you know about" and "what is the".

Second, the teachers showed greater productivity on three types of SLFs; lexical bundles (203), inserts (196), and collocations (166) and produced less idiomatic phrases (7), and binomial expressions (14).The less production of idiomatic phrases is caused by the fact that the teachers tended to use the expressions which showed the actual meaning to communicate with the students to avoid misunderstanding. In addition, lexical bundles became the most frequent type of 
SLFs used by the teachers. It is caused by the fact that the teachers mostly asked questions to students containing whquestion fragments and yes-no question fragments. Moreover, the teachers mostly used imperative and declarative clauses containing more verb phrase fragments and complementizer (if, to, that) or wh- question word introducing dependent clause. Inserts were frequently produced as a proof that they characteristically occur in spoken language (Biber et al., 1999) and the teachers used them spontaneously so that the communication became more interactive. The various kinds of expressions used by the teachers also caused the greater productivity of collocations.

\section{REFERENCES}

Biber, D., Johansson, S., Leech, G., Conrad, S., \& Finegan, E. (1999). Longman Grammar of Spoken and Written English: The Grammar of Conversation. London: Longman.

Celce-Murcia, M. (2007). Rethinking the Role of Communicative Competence in Language Teaching in Intercultural Language Use and Language Learning, Eva Alcón Soler and Maria Pilar Safont Jordà (Eds). Dordrecht, The Netherlands: Springer.

Creswell, J. W. (2014). Research Design: Qualitative, Quantitative, and Mixed Methods Approaches (Fourth Edition). Los Angeles: SAGE.

Hughes, G. S. (1981). A Handbook of Classroom English. Oxford: Oxford University Press.

Nattinger, J. R., \& DeCarrico, J. S. (1992). Lexical Phrases and Language Teaching. Oxford: Oxford University Press.

Smidt, S. (2009). Introducing Vygotsky: A Guide for Practitioners and Students in Early Years Education. New York: Routledge.

Widdowson, H. G. (1989). Knowledge of language and ability for use. Applied Linguistics, 10, 128-137. 